\title{
The Evolution of Social Network Theory: Perceived Impact on Developing Networking Relationships
}

\author{
Robert Cote \\ Lindenwood University
}

The purpose of this research is to explore, analyze, and synthesize seminal and current research on the emerging social network paradigm with a focus on network ties in a various context related to social networking. The research will review and discuss the following topics, including: (1) underlying philosophical orientations, (2) research traditions, (3) methodological approaches, (4) comparison between seminal work and recent research, (5) limitations, and (6) recommendations for further research. Based on the findings, the author recommends further research using more quantitative analysis when comparing independent, dependent, and control variables focusing on network ties in varying contexts or settings to provide more valid and reliable results with objectivity.

Keywords: Social Networking, Networking Relationships, Network Ties, Strength of Strong Ties, Strength of Weak Ties, Structural Holes Theory, Social Network Theory

\section{INTRODUCTION}

For more than thirty five years, the volume of social network research has resulted in accumulated literature in multiple journals. Based on this research, network studies have contributed to the investigation of the wide range of organizational topics, while being analyzed across many levels (Brass, Galaskiewicz, Greve, \& Tsai, 2004; Borgatti, Everett, \& Johnson, 2013). Based on the evolution of "social networking" or "networking", three key researchers have provided the framework, including (a) Barne's (1954) ethnographic fieldwork in Norway has contributed to the extensive research on networking phenomenon in groups, (b) Granovetter's $(1973$; 1983) work on "The Strength of Weak Ties" conducted an analysis on the strength of weak ties in a social network, which has been used in multiple contexts that will be applicable to this study, and (c) Burt (1992) Structural Holes analysis explores the effects a network full of structural holes that provide networking opportunities by connecting individuals to others that are not connected.

In the research on social network theory, researchers have contributed extensively to the body of knowledge in the area of the relationship between the role of strong and weak network ties (Barnes, 1954; Granovetter, 1973; Granovetter, 1983), the influence of hierarchy, centrality and power in an organizational structure (Brass \& Burkhardt, 1990; Brass \& Burkhardt, 1993; Ibarra, 1993), the relationship between actors similarity and network ties in an organization structure (Burkhardt, 1994), and temporal proximity and knowledge sharing (Borgatti \& Cross, 2003). 
In the following sections, social networking terms will be defined, social network theory background will be examined, including Barne's social network theory, Granovetter's strength of week ties, and Burt's structural holes theory.

\section{SOCIAL NETWORKING DEFINITIONS}

For this paper, the terms social networking and networking is defined as a process that individuals develop a relationship with other individuals, based on mutual interests, friendship, interdisciplinary, information, and other beneficial reasons. In the formation of networking relationships with other individuals, the exchange of information and knowledge will provide networking opportunities (i.e., benefits to facilitate innovation) that will evolve and develop over time.

According to Borgatti and Halgin (2011), the following definitions (see Figure 1) provided for network, network ties, and relationships will be referred to in this study. In social networking, a network is a structure of actors or "nodes" referred to as individuals, departments, or groups. Actors are connected and often referred to as ties or connections. The number of reasons for connecting with other actors may include friendship, common interest, interdependency, or other benefits. Actors can be managed by another actor in a one-directional effect when giving advice to another individual. Also, actors can have an indirect effect based on physical proximity to other actors. Actors can have dichotomous connections with other actors whether they are present or absent or whether they have a friendship or not (Borgatti \& Foster, 2003; Borgatti \& Halgin, 2011). The strength between ties will determine the value of the relationship between actors. Borgatti and Halgin, (2011) explain a connection between ties of a given type constitutes a social relation, and each connection of actors defines a different network with connections referred to as a networking relationship. The following list of terms provided with a definition will clarify the meaning used in this paper:

\section{Definitions}

- Actor. Often called "nodes" referred (see Figure 1) as individuals, teams, groups, organizations, and business units (Borgatti \& Foster, 2003).

- Company Networking Activities. Informal and formal meetings developed for interactions between employees in local, regional, national, and global events with a purpose of developing networking relationships and generate new ideas and innovations for the company.

- External Networking Relationships. Relationships are developed with individuals outside governmental agencies.

- Innovation. Defined as a new idea or concept that may be generated by employees, groups, and business units that can be developed into a product that adds value to the organization and customers (Khilji et al., 2006). To further explain, innovation can also be viewed as a result of connections between ties exchanging technology and knowledge in the creation of new products and capabilities (Kastelle \& Steen, 2010).

- Internal Networking Relationships. Relationships developed between individuals in the same department, other departments, groups, business units, and subsidiaries.

- Network. A set of actors are connected to form a network by a set of network ties that can be internal or external (Borgatti \& Foster, 2003).

- Networking Opportunities. The result of networking relationships that are developed and maintained with other individuals with a potential to provide benefits (Forret and Dougherty, 2004).

- Network Ties. Are ties that connect actors in the network. Actors can be connected internally with others in the organization and externally with customers, vendors and suppliers. Based on the type of tie (i.e., binary social relation), the relation will define the different types of networks developed and the strength of the networking relationship between actors (Borgatti \& Foster, 2003). 
- Social Networking or Networking Relationships. Individuals that develop relationships with other individuals; the relationship is formed based on mutual interests, friendship, interdisciplinary, information, and other beneficial reasons. As networking relationships with other individual's evolve, the exchange of information and knowledge will provide networking opportunities that provide benefits over time.

- "Strength of Weak Ties." A theory used to understand the strength of a relationship between ties (Granovetter, 1973: 1983). The theory will be used as the basis of this study to understand the value of the strength of a relationship between ties. In combining a weak tie and a strong tie, individuals can establish a relationship which can develop into a valuable relationship to provide opportunities for both individuals. An example of these opportunities in the pharmaceutical industry can include knowledge exchange, share resources, risk sharing, and collaborate with others to facilitate innovation.

\section{FIGURE 1 \\ SOCIAL NETWORKING DIAGRAM REPRESENTS THE CONFIGURATION OF THE NETWORK, ACTOR(S), AND LINKAGES}

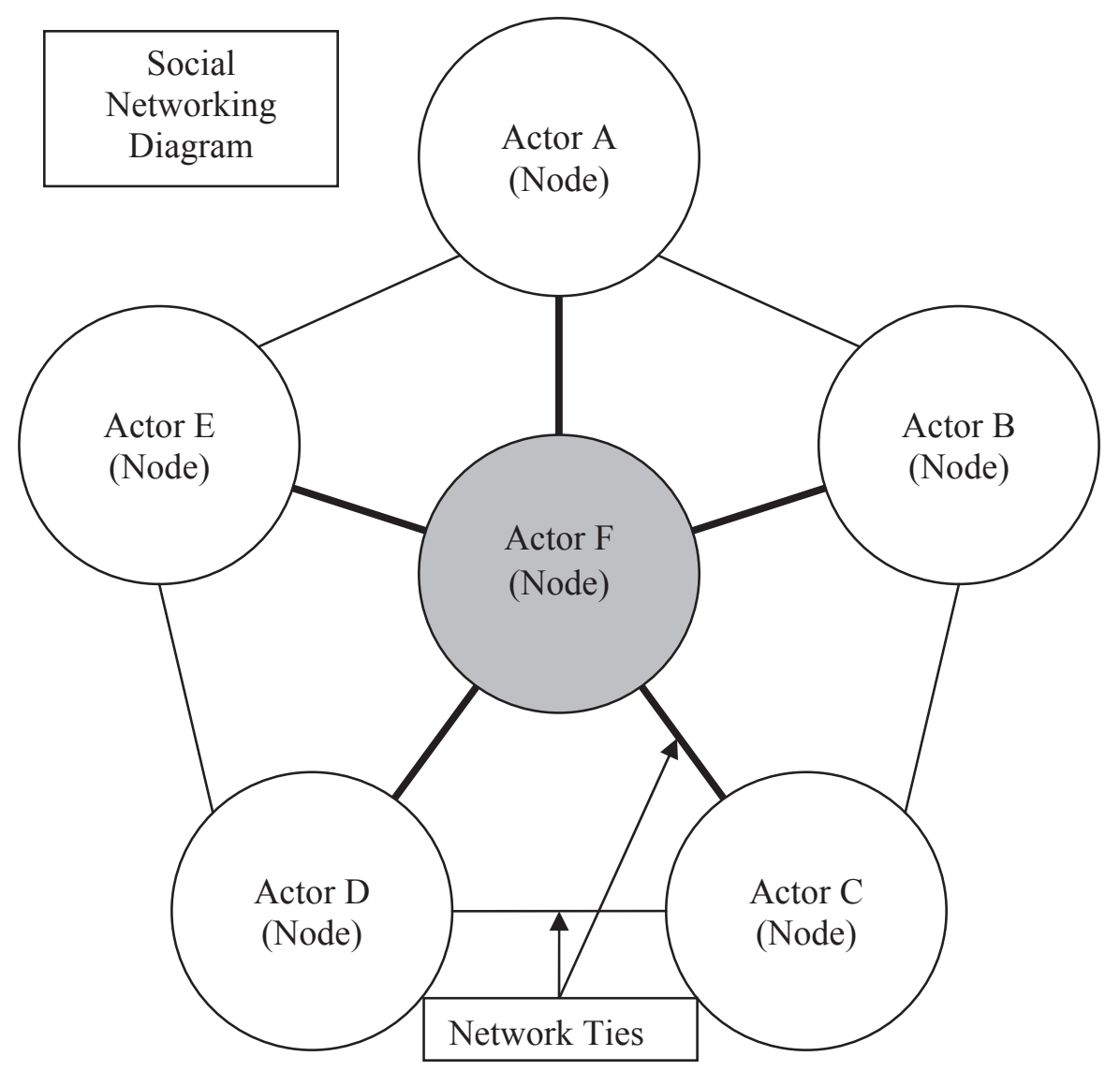


Based on the diagram, circles represent the actor or referred to as node, including individuals, groups, and departments. Lines connecting the circles represent network ties and the entire diagram represents the social network. Adapted from "The Network Paradigm in Organizational Research: A Review and Typology," by Borgatti, S., \& Foster, P., 2003, Journal of Management, 29(6), p. 991. Copyright 2003 by Elsevier Inc.

In the next section, the following key seminal works will be reviewed, including Barnes (1954) field study on social network theory, impact of Barne's seminal research, Granovetter's (1973) "The Strength of Weak Ties" hypothesis, Granovetter's (1983) literature review on SWT, and Structural Holes theory.

\section{SEMINAL RESEARCH ON SOCIAL NETWORK THEORY}

\section{Barnes Social Network Theory}

Social network theory has become a phenomenon based on Barne's (1954) seminal research on social relationships in a small parish in Norway in the 1950's. In this research, Barne's (1954) explored relationships using an ethnographic field study to analyze the relationships of individuals in a social class, thus receiving credit for coining the phrases "networking" and "social networking" used today. In the findings, he concluded relationships between friends, leaders, followers, acquaintances, and followers are based on a combination of strong ties and weak ties that are intertwined within the diverse groups in the social class.

In Barne's (1954) study of the Norwegian parish provided an understanding of network of ties across a social class system. One of the limitations in this study was the size of the setting being studied was small, many members were related, and the society was egalitarian. Based on the limitation in contexts, over the last fifty years many studies have been conducted to answer this question with reproducible results in various settings.

\section{Impact of Barne's Seminal Research}

The impact of Barne's (1954) research has provided the framework for social network theory researched in various business settings and organizational structures with a focus on social relationships, including the influence of hierarchy, centrality and power in an organizational structure (Brass \& Burkhardt, 1990; Brass \& Burkhardt, 1993; Ibarra, 1993; Liu \& Moskvina, 2016), the relationship between actors similarity and network ties in an organization structure (Burkhardt, 1994; Uzzi, 1997), and proximity of individuals and knowledge exchange (Borgatti \& Cross, 2003).

In an effort to further expand the social networking research by Barne's (1954), the following researchers have been influenced by the work and have contributed to the knowledge with an emphasis on the effect of strong or weak network ties. Granovetter (1973) research on "The Strength of Weak Ties", Barne's (1954) ethnographic field study, and Burt (1992) research on Structural Holes provided evidence for understanding the effects of network structure, networking relationships, and network opportunities in individuals, groups, and organizations.

\section{Granovetter Strength of Weak Ties Theory}

In the original social network analysis by Granovetter (1973), he conducted an analysis on the strength of weak ties in a social network using a continuum to measure time, emotional intensity, intimacy, and repetition among connections. This initial research has provided a perspective on the strength of interpersonal ties and the integration between weak ties and strong ties in organizational settings.

In Granovetter (1973) seminal work on the "Strength of Weak Ties," the results support connections of individuals with weak ties generate valuable information in the network when linked to different individuals in smaller to larger groups compared to strong ties. In addition, Granovetter (1973) explains information diffused among weak ties is more apt to reach larger social circles due to the dissimilar and similar social circles in nature. The argument for Granovetter (1973) is interactions among weak ties will probably generate more information that is new and relevant versus a strong tie. These interactions are 
done via a structural bridge or non-redundant connection between different networks or social circles. The structural bridge (see Figure 2) in diagram connects A-B and E-I ties that have no direct or indirect tie that connects two different networks (Burt 1992; Granovetter 1973; Granovetter 1983).

FIGURE 2

NETWORK STRUCTURAL BRIDGE PART A

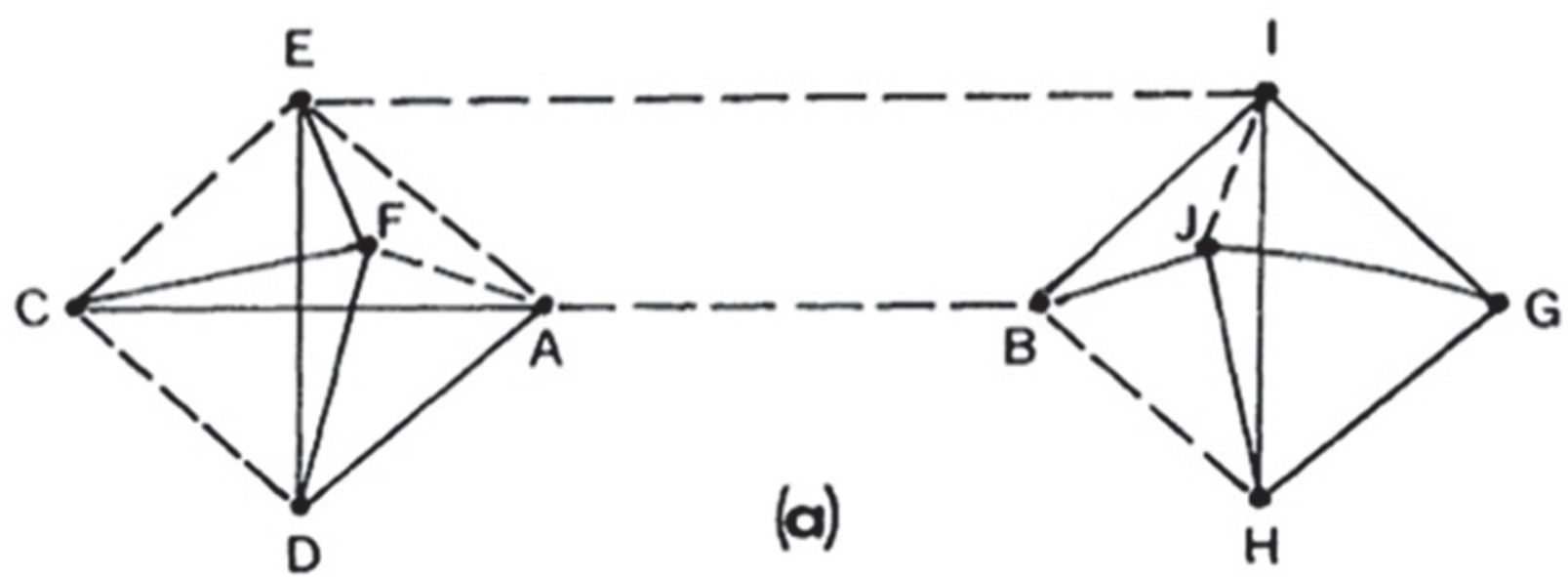

This diagram represents interactions connecting different networks. Letters A, C, D, E, and F are one network and letters B, G, H, I, and J are another network. The dotted lines represent the structural bridges to connect network A-B and network E-I. Reprinted with permission from "The Strength of Weak Ties," Granovetter, M., 1973, American Journal of Sociology, 78(6), p. 1365. Copyright from 1976 by the University of Chicago Press.

Based on the weak ties approach, the interaction among weak ties involve less interaction than strong ties, not dependent on similarity between individuals, and are not embedded in the same networks. In (see Figure 3) diagram, a weaker tie A-B connects individuals that may have unique, diverse, distinctive perspective, and innovative approaches (Hagedoorn, Cloodt, \& Van Kranenburg, 2006; Granovetter, 1973). 
FIGURE 3

NETWORKING STRUCTURAL BRIDGE PART B

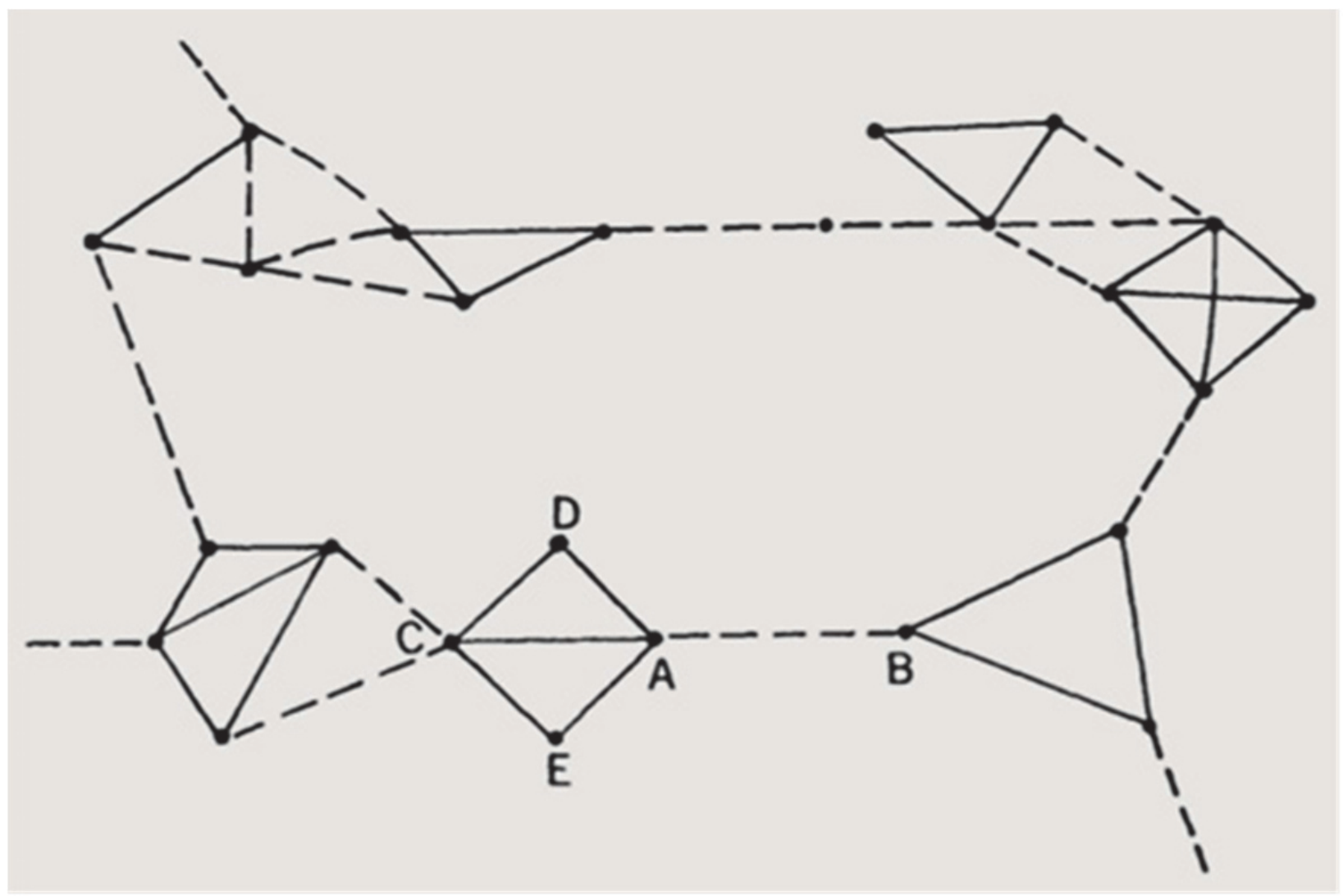

This diagram represents potential interactions connecting different networks. Letters A, C, D, and E are one network that can connect letter B in another network. The dotted lines represent the structural bridges to connect network A-B and networks that are independent non-direct ties. Reprinted with permission from "The Strength of Weak Ties," Granovetter, M., 1973, American Journal of Sociology, 78(6), p. 1365. Copyright from 1976 by the University of Chicago Press.

As individuals connect with other individuals outside their network, weaker ties are connected through the structural bridge and individuals are not familiar with other individual networks by gaining access to diverse networks. In the weak tie argument, stronger ties are not apt to be connected through a structured bridge and be more familiar with each other's networks. In a strong tie, individuals interact more frequently and tend to gravitate among similar interrelated networks having the potential of reaching high redundancy. For recipients receiving information through a weak tie, it is more likely to be diverse and non-redundant while providing access to new information beneficial to innovation (Granovetter, 1973).

Although the initial research by Granovetter (1973) has provided a perspective on the strength of interpersonal ties and the integration between weak ties and strong ties in organizational settings. In the seminal work by Granovetter (1973), his research has provided evidence on the benefits of strong and weak ties. Some of the limitations noted in his research, include: understanding the value of relationship between ties, the strength of ties and hierarchical structure in organizations, and the effects of negative ties (Granovetter, 1973). 


\section{Granovetter 1983 Research on Strength of Weak Ties}

Based on the previous research by Granovetter (1973), a review was conducted to further test "The Strength of Weak Ties" hypothesis to ascertain whether acquaintances (weak ties) are less likely to be socially involved with one another compared to close friends (strong ties). In Granovetter (1983) review, the following results were shared in the conclusion of his research. In weak tie connections with individuals, the relationship is less likely to be socially involved compared to a strong tie with friends. Individuals of strong ties are motivated in providing assistance to others and more accessible while weak ties provide information and resources. In Granovetter's $(1973 ; 1983)$ research, developing relationships that provide benefits is based on the connection of an individual with a group of weak ties with an individual with a group of strong ties. In an organization, this is a crucial bridge for two groups of individuals to collaborate in developing relationships that provide benefits, including new knowledge, new perspectives, and diverse information. In companies, establishing relationships with weak and strong ties enables individuals to prosper in a collaborative effort with internal and external connections. These relationships will further utilize resources and knowledge exchange in the development of new ideas, concepts, products and technologies.

In the findings, a common limitation on the weak tie hypothesis concluded many studies were theoretical efforts lacking empirical data. The review supported the original argument that weak ties serve their function when bridged between network segments. For further research, a systematic investigation on the origin of network ties that bridge compared to those that do not bridge would provide context on the methods individuals connect between bridges (Granovetter, 1983).

Based on Granovetter's $(1973 ; 1983)$ seminal research on weak ties, the research provided an exploratory rationale for the analysis of the strength of interpersonal ties in different contexts. However, in all research there are limitations that need further research to answer questions of inquiry and add to the existing base of knowledge. In Granovetter's $(1973$; 1983) research, the following limitations for future research on weak ties include (a) relationship between the ties, (b) strength of ties in hierarchical organizational structure, (c) importance of the value between ties, and (d) impact on negative ties or gaps in connections between ties. Based on one of the limitations of Granovetter (1973), Burt (1992) was able to further research and adds knowledge to the understanding of gaps between connections in the Structural Holes theory.

\section{Structural Holes Theory}

To further expand Barne's (1954) research on networking and Granovetter's $(1973 ; 1983)$ gap between connections, Burt (1992) conducted his research on Structural Holes. In the analysis, the basis for the research is to examine the dynamics of relationships between individuals in a competitive field within an organization. His argument states "that much of competitive behavior and its results can be understood in terms of player to access to 'holes' in the social structure of the competitive arena" (p. 1).

Burt (1992) explains the competitive field consists of a diverse group of individuals connected to other individuals. In these connections, the relationships may be based on developing trust, supporting others, or be dependent on others for the exchange of information or resources. In the network configuration (see Figure 4) diagram, the following information will be described, including the network ties between individuals are interchangeable with other individuals in the network (i.e., social structure), structural holes do exist in the network and are referred to as "holes" that minimize connections between individuals because they are not directly connected with others in the network. Having a network abundant of structural holes will provide opportunities for individuals to connect with as many individuals who are disconnected. These connections may enhance information exchange.

Burt (1992) summarizes the benefits of the structural holes argument by explaining the theory is based on a competition of opportunities and constraints among individuals with similar resources and information are separated by a structural hole. As a means to fill the gap between these individuals, a third individual will join the individuals giving them a competitive advantage.

How can the Structural Holes Theory be applied in the business industry? Companies form collaborations/alliances within their organizations and externally with other companies, vendors, 
suppliers, and customers to facilitate communication through the exchange of diverse information. The configuration of structural holes provide the following benefits in developing networking relationships, including network ties occur unexpectedly with other individuals, individuals not connected can develop relationships with other individuals through an introductions with a 3rd party, structural holes provide a competitive environment allowing individuals the ability to connect or withdraw with others based on the benefits of the relationship, and structural holes in the network may provide individuals a competitive advantage for negotiating relationships based on the degree and extent of individuals relationship.

FIGURE 4

STRUCTURAL HOLES DIAGRAM

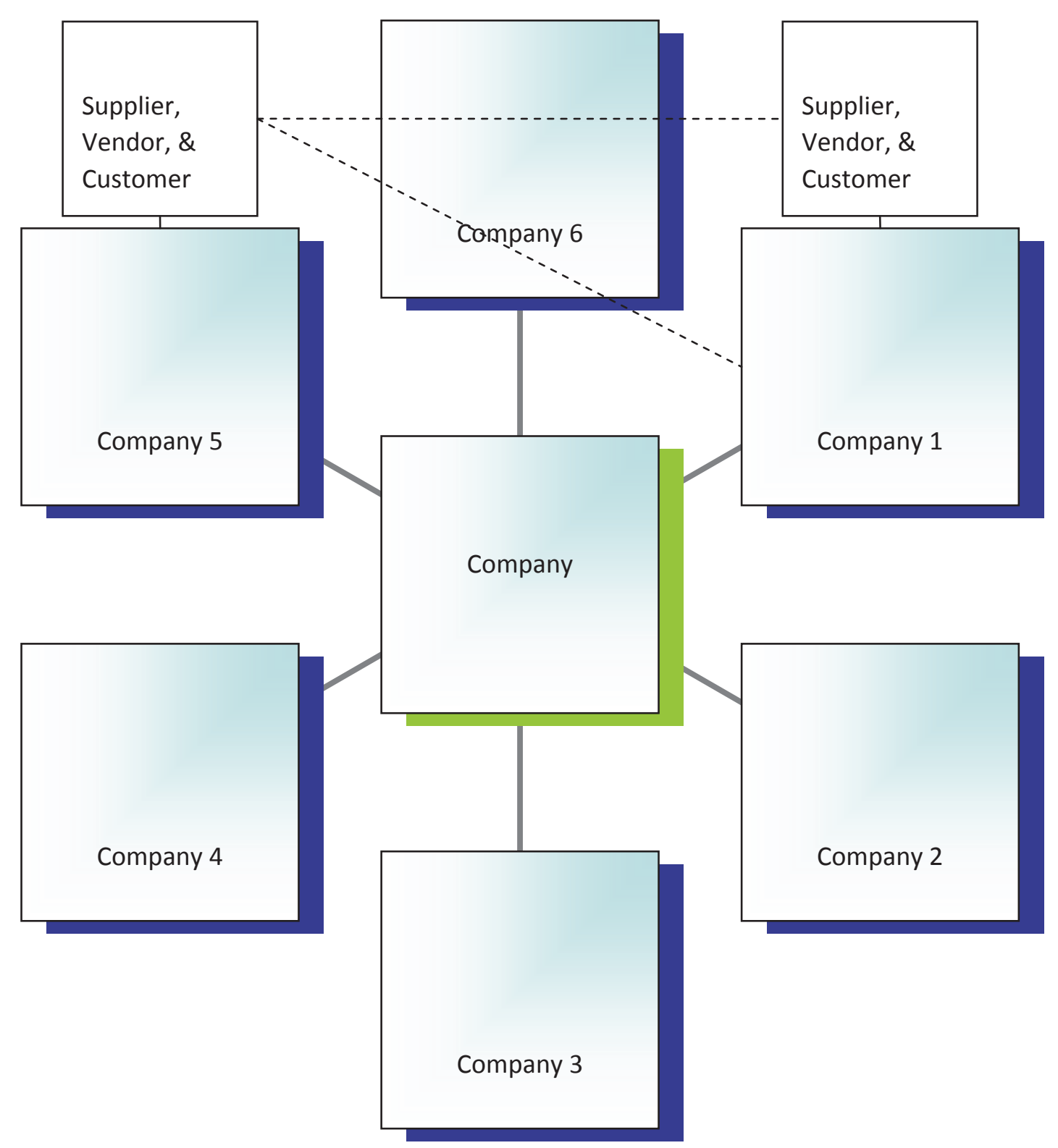


The diagram illustrates the network structure of a Company and other companies in the business industry. Solid black lines are network connections between companies. The dotted lines are indirect connections between companies creating structural holes between connections. Adapted from "Structural Holes: The Social Structure of Competition," by Burt, R., 1992. Copyright 1992 by President and Fellows of Harvard College.

The Structural Holes argument is similar to Granovetter (1973) "Strength of Weak Ties" except Burt (1992) network is based on connecting as many individuals that are unconnected, defined as structural holes or gaps in the network creating opportunities. Granovetter (1973) network is based on individuals being connected based on strength of relationship with other individuals, such as friends, family, and acquaintances.

\section{Structural Holes Limitations}

In Burt (1992) initial research on Structural Holes, Andrews (1995), Krackhardt (1995), and Salancik (1995) provide a few limitations based on the review of Structural Holes. Krackhardt (1995) limitation is based on a comparative analysis of individuals competing in similar or different markets. How can the interactions of individuals in one market have different behaviors of individuals in another market, thus creating a constraint while both individuals are playing by the same rules in the game set by the same organization, market, or society? Andrews (1995) limitation relates to a paradox on why individuals in structurally disadvantageous positions cannot freely create entrepreneurial relationships. Although, these positions are perceived to be an advantage, is the reason because the constraints deter the opportunity or the individual cannot remove the constraints? The last limitation is focused on organization theory and network analysis. At the time of Structural Holes, research focused on the actions of individuals within the organization compared to the actions of organizations. For further research, Salancik (1995) suggests exploring networking relationships and influence on inter-firm interactions. Since the seminal work in 1992, limitations were noted in 1995 and further research has been conducted to explore the positive and negative outcomes of the structural holes phenomenon. In a longitudinal study, Ahuja (2000) explores a network of interfirm collaborative linkages and innovation output. In the findings on structural holes, indirect ties can provide benefits to the interfirm linkages by enabling knowledge spillover to increase innovation output. Indirect ties compared to direct ties require minimal maintenance for the firm while increasing network effectiveness. On the other hand, the results suggest three cautions to be considered before building large networks of indirect ties, are (1) direct ties provide resource sharing and knowledge spillover, while indirect ties only provide the later, (2) benefits of indirect ties may be significantly less than direct ties, although they provide similar results. For example, indirect ties may provide an extension of the network to gather information or resources and also may be the competitor in the same network, and (3) a potential negative interaction between indirect and direct ties may be the result of the combination of indirect to direct ties and vice-versa. Due to the access to the same information, flexibility, alertness, and responsiveness to be considered in profiting from information shared between ties. The continued research on structural holes will provide an understanding on this phenomenon in various contexts.

In the next section, research that has been conducted over the last thirty years on social network theory will be further analyzed, including research on the areas of technology change in federal agency, technology choice in telecommunications industry, and technology IT-induced change in financial company, innovation and networking, and Networking and Entrepreneurial Business Activity. The following areas will be discussed, which are philosophical orientations, research traditions, and methodological approaches. 


\section{RESEARCH ON SOCIAL NETWORK THEORY}

\section{Technology Change, Technology Choice, and Network Ties}

In a longitudinal quantitative study, Burkhardt and Brass (1990) collected questionnaires from eighty one full-time employees in a federal agency. The purpose is to investigate the effects of technology change and power in an organizational structure. Research questions proposed are "Does the diffusion of new technology follow established network patterns, with those in power reinforcing their positions?" or "Does the introduction of uncertainty result in changing patterns of interaction and influence?" Based on the methodology of the study, the author would assume a positivist approach. Creswell (2009) states positivist is "what is posited or given in direct experience is what is observed" (p. 20). He further explains this approach is carried out by the scientific method which was conducted in this study. The phenomena of social network influenced the authors to further research on this topic. The interpretivist approach was based on understanding how technology change will have on the social member's situation. The ontological orientation was based on the opportunity to provide contributions toward the previous research on technology change and social network in an organizational structure.

Data was collected through questionnaires in four time points with the following network measures being analyzed, which are: (1) closeness measure of centrality based on strong and weak ties, (2) indegree is a second measure of centrality focusing on direct employee connections, (3) Power was assessed using a 5-point Likert-type scale, (4) five individual characteristics were measured, and (5) computer efficiency using 7-point Likert scale. In the results section, the hypotheses were tested for characteristics in early adopters in network centrality and power using hierarchical regression analysis, multivariate analysis was used to assess change in power over time in adopters, and cross-lagged correlations were used to measure power and network centrality (Burkhardt \& Brass, 1990).

Based on the results, Burkhardt and Brass (1990) concluded the focus on stability and change showed "considerable change in both structure and power occurred" (p. 119). They further concluded the influence of individuals increased as centrality increased due to the strong interconnection ties within the network to accommodate diffusion of new technology.

Based on the authors identified limitations, Burkhardt and Brass (1990) identified the following limitations. The lack of a control group was an internal validity threat in the study due to the design involving all employees and were all subjected to the change in the technology diffusion. As a result, it would be difficult to identify and study a control group of employees that did not experience change. The lack of non-reputational measures of power, such as non-supervisors compared to supervisors could be avoided by using a multiple-rater methodology to reduce internal validity threats. For external validity, the generalizability may be limited for the application of this particular type of technology diffusion (change) to organizational change or other technology change. Based on the limitations, the authors indicate the combination with the previous technology change studies would provide additional knowledge in accounting for this type of technology change (Burkhardt \& Brass, 1990).

In a quantitative theoretical study, Suarez (2005) investigates the role of strong ties in technology selection by proposing a discrete-choice model to be tested in the wireless telecommunications industry. Prior research has focused on empirical studies exploring technology adoption and has viewed the size of the network size the measure of the strength impacting strength effects. The positivist approach was based the methodology for testing variables on network and an ontological orientation influenced by Granovetter's (1973) SWT, Kraatz (1988), and Uzzi's (1997) previous research on strong ties. Based on Suarez (2005) theoretical study, his findings may conceptualize and provide meaning to the existing knowledge on the strength of weak and strong ties.

Unlike the SWT perspective in a larger network in telecommunications industry, Suarez (2005) provides evidence to support his hypothesis using the strength of strong ties. The evidence conveys a benefit to this industry by providing stability by adapting to environmental uncertainty with a smaller dense network. Based on the findings, Suarez (2005) concludes the results support hypothesis 2, "strongties network effects are stronger than classical network effects as predictor of the probability that a user chooses a given technology over competing alternatives" (p. 712). He further explains cellular operators 
are influenced by the selection of the list of geographical places where the entering operators expect to have the strongest ties (Suarez, 2005).

Based on the limited research in the area of industrial economics and social network theory, the author believes this study will help cross-pollinate and bring new and valuable insights in this subject matter. For further research, studies should be conducted in other situations evaluating the nature of ties based on the relevance of network effects and additional research should be noted in relating the role of the network effects in the various stages of the value system (Suarez, 2005).

In a qualitative study, Bruque, Moyano, and Eisenberg (2008) examined the role of supportive and informational social networks in a financial institution adaptation to an IT-induced change. The author's interviewed 371 employees across 133 different branches using on-site employee's to conduct the interview to ensure dependability. Prior empirical evidence conducted on the relationship between ITinduced technology change and social network structures ties, which has provided an opportunity to contribute to the knowledge (Bruque, et al., 2008).

The previous work by Barnes (1954), Granovetter's (1973), and Granovetter's (1983) work on SWT influenced Bruque et al. (2008) to further research network ties with an ontological philosophical orientation. The interpretivist approach has an underlying positivism based on the scientific method used to test the hypothesis and interpretation of the results on social networks and IT-induced change.

In the findings, the positive effect correlated to the size of the supportive social networks by providing value to employees in knowledge sharing, performance feedback, encouragement in assisting adaptation to IT-induced change. Some of the limitations mentioned by the authors are: (1) use of a crosssectional approach instead of a longitudinal research design may have broadened the analysis, (2) did not include important factors such as formalized training instead of focusing on informational and support networks that affect individuals adaptation, and (3) psychological mechanisms of self-efficacy and coping would be instrumental for effective adaptation (Bruque et al., 2008).

Based on the limited research in the area of industrial economics and social network theory, the researcher believes the study will help cross-pollinate and bring new and valuable insights in this subject matter. For further research, studies should be conducted in other situations evaluating the nature of ties based on the relevance of network effects and additional research should be noted in relating the role of the network effects in the various stages of the value system (Suarez, 2005).

\section{Mobility in the Workplace}

Podolny and Brass (1997) conducted a qualitative study examining social network ties and mobility in the workplace. The author's ontological orientation was influenced by Granovetter's (1973) SWT concept to further contribute to the knowledge. In previous studies, results showed weak ties may provide new information to the group compared to the strong ties in a social group, while the weak ties may enable individual's mobility to be enhanced through a large, sparse network of informal ties. The research tradition would be an interpretivist approach with an underlying positivism based on the scientific method used to test the hypothesis on social networks and mobility. The authors surveyed 25,000 employees in a technology organization to explore how the effects of structural holes on mobility vary across different types of network ties based on five types of social relations, which are task advice, strategic information, "buy-in" or "fate control", social support, and mentorship. Based on the findings, the informal ties created provide individuals additional resources, information, and have a sense of belonging. Constraints identified are: (1) opportunity to form new ties based on value of future mobility, (2) limited opportunity to form ties based on same multiple contents, such as strategic information, receiving task advice, and social support, and (3) negative reputation in dropping person-to-person ties due to value proposition. Based on organizational constraints, a future research suggestion would be focusing on the employees strategic choices in forming social ties and the impact of informal social networks impact mobility and job satisfaction in the workplace. The information will help in providing a better insight on mobility in the organization (Podolny \& Brass, 1997). 


\section{Innovation and Networking}

In the literature review, Pittaway, Robertson, Munir, Denyer, and Neely (2004) provides a systematic review of empirical research linking networking and innovation in firms in the United Kingdom (UK). The literature review structure contained an introduction, methodology, and conclusion similar to a research article. The interpretivist research tradition was based on the methodology for selecting and analyzing companies in the UK. The methodology used for selecting companies is based on the following themes, which are: (1) network formation, (2) diversity of partners, (3) suppliers, (4) institutional factors, (5) customers, (5) third parties, (6) science partners and finance partners, (7) network behavior, governance, management, and configuration. In the review process, 628 papers were identified and 332 were considered relevant. In the 332 papers, they were categorized into A, B, and C lists resulting in a final number of 179 papers for the study. The timeframe used for the review was1981-2003 with the most relevant articles located between the years of 1999-2003. The industries identified were primary industries, manufacturing industries, service industries, and high-technology industries (Pittaway et al., 2004).

Based on the selection process, the following criteria were established, which are: (1) the authors organized the findings based on networking and technology innovation, (2) companies based in the UK, United States, and Germany, and (3) evidence reviewed was prioritized based on relevance and prolonged timeframe. Based on the analysis and synthesis of the literature, the authors used tables, figure to demonstrate networking infrastructure, and an appendix for quality criteria to organize and present their research findings (Pittaway et al., 2004).

Based on the review, Pittaway et al. (2004) identified the following benefits of networking, including: (a) pooling complementary skills, (b) risk sharing, (c) speeding products to market, (d) obtaining access to new technologies and markets, (e) safeguarding property rights in situations when contingent or complete contracts are not possible, and (f) gaining access to external knowledge. Also, the authors illustrate a limitation in firms that do not co-operate with other forms either formally or informally in exchanging knowledge may limit their knowledge base an opportunity to enter a networking exchange relationship. Also, the review of evidence on networking and innovation highlighted a number of gaps for future research, which are networking and types of innovation, network dynamics and configuration for successful innovation, understand the diversity of partners and innovation, facilitating networking through institutional mechanisms and their impact on innovation (Pittaway et al., 2004).

\section{Networking and Entrepreneurial Business Activity}

In a qualitative ethnographic study, Jack (2005) conducted interviews by selecting fourteen respondents using theoretical sampling to explore in-depth networking. The ontological philosophical assumption was based on the methodology and introduction of a theoretical perspective to further understand network ties. According to Crotty (1998), the interpretivist approach, "looks for culturally derived and historically situated interpretations of the social life-world" (p. 67). The author used an ethnography strategy to study the group in a natural setting to collect information and provide a guiding framework for the research. The context was based on a rural area in Scotland focused on entrepreneurial activity, influence on relationships, and significance of social networks. The information was gathered through interviews, documents, observations, and discussions. The cases were analyzed and compared to determine ties and networks (Jack, 2005).

Jack's (2005) influence is based on Granovetter's (1973) SWT hypothesis to further expand this research with a theoretical contribution to enrich and understand the strong and weak hypothesis by enhancing an understanding of the role of ties in business activity with entrepreneurs. The following research questions were proposed, "What is the role of ties? How are ties used to be activated?" (p. 1234).

In the results section, the interpretative results correlated to the research question concluding respondents showed strong ties affiliated with familiar links, such as family, friend, personal, and employee in business activity. In a comparison of Jack's (2005) ethnographic study to Granovetter's (1973) work on SWT, the results showed little evidence to support weak ties due to the nodes of strong ties operating in a small social context. 
A couple of the limitations noted by Jack (2005) are, external (transferability) and internal (credibility) validity threats due to the restricted study area that limited the number of entrepreneurs (selection of subjects) and the methodology (research strategies) used may inhibit generalizability in other settings (Creswell, 2009; Trochim, 2006). Although Jack (2005) defends her limitation by stating "the respondents are not representative of the entrepreneurial universe, they do provide useful data on the nature of network ties" (p. p. 1242). She further explains the data supports the benefits of strong ties by demonstrating the "function" of the tie is more important for entrepreneurship when building and forming ties than the frequency of interaction between the ties. Therefore, the findings in this study propose that strong ties developed by entrepreneurs increase information and resources in their business activity (Jack, 2005).

In the next section, a comparison between Barne's (1954), Granovetter's (1973; 1983), and Burt's (1982) research will evaluate the benefits of networking and limitations of networking across multiple industries and levels.

\section{COMPARING AND CONTRASTING BENEFITS AND LIMITATIONS OF NETWORKING}

\section{Benefits of Networking}

In the seminal work by Barne's (1954), Granovetter's (1973; 1983), and Burt's (1982), the research have provided the theories to support the framework and the basis for further research on networking in business, organizations, and multiple industries. The results concluded in Barne's (1954) research support that diverse relationships between acquaintances, friends, and followers provide an arrangement of strong and weak ties intertwined between individuals in a social setting. Granovetter's $(1973 ; 1983)$ findings showed weak ties (acquaintances) of individuals are more likely to link individuals of different smaller groups to larger groups compared to strong ties (close friends \& family) resulting in more valuable information being generated in the network. Burt's (1992) findings explained a network abundant of structural holes (disconnections) between individuals or companies create a competitive network. In this network, the competition among individuals is based on the relationships that intersect creating structural holes for the enhancement of opportunities, including exchange of information and diverse knowledge.

The current research has demonstrated the beneficial effects of networking and has provided an abundance of literature in various contexts, including pharmaceutical companies, biotechnology companies, multiple industries, and international firms. In the findings, networking concluded that relationships developed between actors (e.g., individuals, groups, and companies), diversity of the relationship (i.e., collaborations and alliances), and strength of the relationship provide many benefits, including the following benefits, including access to external knowledge, new markets and technologies, combining complementary skill sets, and reducing risk. Also, the results provided evidence those relationships with customers, suppliers, vendors, and other companies affect developing relationships, collaboration, information exchange, performance, and productivity.

\section{Limitations of Networking}

In the review of current literature, limitations have also been acknowledged that need to be further researched to answer questions of inquiry and the unknown. For limitation on networking, gaps on understanding networking opportunities and forms of innovation (e.g., product, process, or organizational) need to be more clearly defined. Also, having a better understanding of the diversity of networking relationships between actors may provide clarity on how to facilitate innovation in companies. 


\section{CONCLUSION}

In the last thirty five years, social network theory has become a popular subject matter to research with the accumulation of literature in the management journals. The majority of the studies reviewed have used a qualitative analysis, field research, case studies, and ethnographic observations focused on organizational structure and business activity, including the influence of hierarchy, centrality and power in organizations (Brass \& Burkhardt, 1990; Brass \& Burkhardt, 1993; Ibarra, 1993), the relationship between actors similarity and network ties in organizational structure (Burkhardt, 1994), temporal proximity and knowledge sharing (Borgatti \& Cross, 2003), technology diffusion (Brass \& Burkhardt, 1990), mobility in the workplace (Podolny \& Baron, 1997), and Innovation and networking (Pittaway et al., 2004). Compared to the seminal work of Barnes (1954) ethnographic fieldwork in Norway, Granovetter's (1973) strength of weak ties concept, and Granovetter's (1983) review on his previous work have contributed extensively in the research on social network theory and social networking phenomenon.

Based on data collection, researchers have used participant observation, surveys, interviews, and questionnaires, and ethnographic observation, the results are more subjective interpretation compared to an objective interpretation. Criteria that may impact credibility, dependability, and confirmability are the varying methods instruments, observers, and participant's perspectives have provided inconsistent results in some of the studies. These limitations have been noted by the researchers. Criteria noted in the studies that may impact transferability, is the inconsistent contexts or settings in the studies varied in organizational structures, industries, and treatment groups. Based on these limitations, the author's suggestion would be the utilization of more quantitative studies comparing independent, dependent, and control variables in social network theory focusing on network ties in varying contexts and settings.

For further research, in the studies conducted by Jack (2005) and Suarez (2005) studies, the authors provide evidence to support recommendations for further research on the strength of strong ties. Since the early works of Granovetter's (1973) SWT, the strengths of ties concept has provided another perspective to consider, focusing on the benefits of the strength of strong ties. In Suarez (2005), he suggests the strength of strong ties may provide benefits to organizations attempting to adapt to environmental times of uncertainty according to Kraatz (1998) and Uzzi (1997). Based on these findings, for further research on network ties, this author would like to explore the strength of weak ties and strength of strong ties in an analytical review by analyzing and synthesizing the evidence comparing these perspectives. 


\section{REFERENCES}

Ahuja, G. (2000a). Collaboration networks, structural holes, and innovation: A longitudinal study. Administrative Science Quarterly, 45(3), 425-455. Retrieved from Business Source Complete database

Ahuja, G. (2000b). The duality of collaboration inducements and opportunities in the formation of interfirm linkages. Strategic Management Journal, 21(3), 317. Retrieved from Business Source Complete database.

Barnes, J. A. (1954). Class and committees in a Norwegian island parish. Human Relations, (7),39-58. Retrieved from Michigan Information Transfer Source.

Borgatti, S., \& Cross, R. (2003). A relational view of information seeking and learning in social networks. Management Science, 49(4), 432-445. Retrieved from Business Source Complete database

Borgatti, S., \& Foster, P. (2003). The Network Paradigm in Organizational Research: A review and typology. Journal of Management, 29(6), 991. Retrieved from Business Source Complete database

Borgatti, S., \& Halgin D. (2011). On network theory. Organization Science, 22(5), 1359-1367.

Borgatti, S., Everett, M., \& Johnson, J. (2013). Analyzing Social Networks. Los Angeles: Sage.

Brass, D., Galaskiewicz, J., Greve, H., \& Tsai, W. (2004). Taking stock of networks and organizations: A multilevel perspective. Academy of Management Journal, 47(6), 795-817. Retrieved from Business Source Alumni Edition database

Brass, D., \& Burkhardt, M. (1990). Changing patterns or patterns of change: The effects of a change in technology on social network structure and power. Administrative Science Quarterly, 35(1), 104127. Retrieved from Business Source Alumni Edition database

Brass, D., \& Burkhardt, M. (1993). Potential power and power use: An investigation of behavior. Academy of Management Journal, 36(3), 441-470. Retrieved from Business Source Complete database

Burkhardt, M. (1994). Social interaction effects following a technological change: A longitudinal investigation. Academy of Management Journal, 37(4), 869-898. Retrieved from Business Source Alumni Edition database

Bruque, S., Moyano, J., \& Eisenberg, J. (2008). Individual Adaptation to IT-Induced Change: The Role of Social Networks. Journal of Management Information Systems, 25(3), 177-206. Retrieved from Business Source Complete database

Burt, R. (1992). Structural holes: The social structure of competition. Cambridge, MA: Harvard University Press.

Creswell, J. W. (2013). Qualitative inquiry \& research design: Choosing among five approaches ( $3^{\text {rd }}$ ed.). Thousand Oaks, CA: SAGE.

Creswell, J.W. (2009). Research design: Qualitative, quantitative, and mixed methods approaches ( $3^{\text {rd }}$ ed.). Thousand Oaks, CA: Sage.

Crotty, M. (1998). The foundations of social research: Meaning and perspective in the research process. Thousand Oaks, CA: Sage Publications.

Forret, M., \& Dougherty, T. (2004). Networking behaviors and career outcomes: differences for men and women? Journal of Organizational Behavior, 25(3), 419-437. doi:10.1002/job.253.

Granovetter, M. (1973). The strength of weak ties. American Journal of Sociology, 78(6), 1360-80.

Granovetter, M. S. (1983). The strength of weak ties: A network theory revisited. Sociological Theory,1, 201-233. Retrieved from Michigan Information Transfer Source

Hagedoorn, J., Cloodt, D., \& Van Kranenburg, H. (2006, June). The strength of R\&D network ties in high-tech industries: A multi-dimensional analysis of the effects of the strength on technical performance. Paper presented at the DRUID Summer Conference on Knowledge, Innovation and Competitiveness: Dynamics of Firms, Networks, Regions, and Institutions, Copenhagen, Denmark. Abstract retrieved from http://www2.druid. dk/conferences/viewpaper.php?id = 39\&cf $=8$ 
Ibarra, H. (1993). Network centrality, power, and innovation involvement: Determinants of technical and administrative roles. Academy of Management Journal, 36(3), 471-501. Retrieved from Business Source Complete database

Jack, S. (2005). The role, use and activation of strong and weak network ties: A qualitative analysis. Journal of Management Studies, 42(6), 1233-1259. Retrieved doi:10.1111/j.14676486.2005.00540.x

Kastelle, T., \& Steen, J. (2010). Are small world networks always best for innovation? Innovation: Management, Policy \& Practice, 12(1), 75-87. doi:10.5172/impp.12.1.75

Khilji, S., Mroczkowski, T., \& Bernstein, B. (2006). From invention to innovation: toward developing an integrated innovation model for biotech firms. Journal of Product Innovation Management, 23(6), 528-540. doi:10.1111/j.1540-5885.2006.00222.x

Kraatz, M. (1998). Learning by association? Intraorganizational networks and adaption to environmental change. Academy of Management Journal, 41(6), 621-643. Retrieved from Business Source Complete database

Krackhardt, D. (1995). Structural Holes: The social structure of competition. Administrative Science Quarterly, 40(2), 350-354. Retrieved from Business Source Complete database.

Liu, J., \& Moskvina, A. (2016). Hierarchies, ties and power in organizational networks: model and analysis. Social Network Analysis and Mining, 6. 10.1007/s13278-016-0413-2

Pittaway, L., Robertson, M., Munir, K., Denyer, D., \& Neely, A. (2004). Networking and innovation: a systematic review of the evidence. International Journal of Management Reviews, 5/6(3/4), 137168. Retrieved from Business Source.

Podolny, J., \& Baron, J. N. (1997). Resources and relationships: Social networks, mobility, and satisfaction in the workplace. American Sociological Review, 62(5), 673-693.

Salancik, G. (1995). Wanted: A good network theory of organization. Administrative Science Quarterly, 40(2), 345-349. Retrieved from Business Source Complete database

Suarez, F. (2005). Network effects revisited: The role of strong ties in technology selection. Academy of Management Journal, 48(4), 710-720. Retrieved from Business Source Complete database

Trochim, W. (2006). Research methods knowledge base. Retrieved from http://www.socialresearchmethods.net/kb/introval.php

Uzzi, B. (1997). Social structure and competition in interfirm networks: The paradox of embeddedness. Administrative Science Quarterly, 42(1), 35-67. Retrieved from Business Source Complete database.

Uzzi, B., \& Spiro, J. (2005). Collaboration and creativity: The small world problem. American Journal of Sociology, 111(2), 447-504. Retrieved from Business Source Complete database 